Spatial Enablement to Facilitate the New Urban Agenda Commitments for Sustainable Development

\title{
Soheil Sabri
}

Centre for SDIs and Land Administration, The University of Melbourne, Australia

\author{
Abbas Rajabifard \\ Centre for SDIs and Land Administration, The University of Melbourne, Aus- \\ tralia
}

In the context of SDGs, this chapter talks about spatial enablement to facilitate the New Urban Agenda commitments for Sustainable Development. It discusses historical account of how global began to be considered a threat and how it ended up as a potential development tool for the future generation established by the New Urban Agenda. The Chapter introduces the elements of action framework for the implementation of a selected case studio in Singapore. The chapter will come to an end with describing the future opportunities in research and capacity development in support of evidence-based and data-driven urban policy and planning.

\subsection{Introduction: Background and Driving Forces}

In light of rapid urbanisation worldwide, the complexity of cities is ever increasing, which complicate urban planning and management tasks. One of the major challenges is the limited capabilities offered by conventional approaches to urban and regional development and management [12]. Addressing current challenges created by urbanisation requires cutting-edge, interoperable tools and expertise, localised for each country and domain of application adopted and adapted from best practices worldwide to meet international standards (e.g. Sustainable Development Goals) [17]. 
Over the last four decades, several international organisations have developed standard indicators to foster nations to set, measure, monitor and evaluate development policies. Examples for these standards are Millennium Development Goals (MDGs) and Sustainable Development Goals (SDGs) adopted by the United Nations and member states in 2000 and 2016 respectively $[18,8]$. Accordingly, other international and national organisations have developed initiatives, indicators and indices such as the New Urban Agenda, ISO 37120 urban sustainability indicators, and the City Prosperity Index for ensuring quality of life challenges are linked to sustainable development policies, strategies, and decision making $[6,12,20]$.

In 2016, the United Nations Conference on Housing and Sustainable Urban Development (Habitat III) in Quito, Ecuador, adopted the New Urban Agenda (NUA). For the first time, Habitat III acknowledged cities as potentially the source of solutions rather than the cause of challenges the world is facing with. The NUA declared that, if well-planned and well-managed, urbanisation can be a powerful tool in achieving the sustainable development status in developing and developed countries [17]. Five main pillars of NUA implementation lay out the standards and principles for planning, development, construction, improvement, and management of urban areas:

1. National urban policy; "the National Government is the level that holds the sovereignty of the nation, and it establishes the rules and functions of the subnational and local governments."

2. Urban legislation and regulations; "good urbanisation cannot be conceived without a good regulatory framework."

3. Urban planning and design; "urban planning and design is an essential technical part of the urbanization process and it refers to the physical layout of buildable plots, public space, and their relationship to one another. In line with the NUA, UN-Habitat believes that urban planning of design is a fundamental priority to achieving sustainable urban development."

4. Local economy and municipal finance; "one of the novelties of the urban paradigm shift of the NUA is the contribution of urbanization to the national economy. Urbanization should be approached not as a cost, but as an investment, because the cost of urbanization is minimal compared to the value that it can generate."

5. And local implementation; "as an important action plan, this pillar encourages spatial development strategies that take into account, as appropriate, the need to guide urban extension prioritising urban renewal by planning for the provision of accessible and well-connected infrastructure and services, sustainable population densities, and compact design and integration of new neighbourhoods into the urban fabric, preventing urban sprawl and marginalisation."[17] 
There have been extensive works to adopt the above-mentioned initiatives, standards and indicators to local policy and development strategies. As an example, UN-Habitat drafted an Action Framework for Implementation of the New Urban Agenda (AFINUA), which aimed to guide the implementation of the NUA, with necessary ingredients to lead each, identifying methods of measurement and their link to the provisions of the NUA. There are 35 key elements that group into the above-mentioned five main pillars of NUA [16].

However, recent studies indicate a weak connection between some of the indicators and government policies and decision making. Deng et al., (2017) highlight that city managers have been slow to adopt the urban sustainability indicators in their decision-making process due to the lack of unique interpretation by the urban experts [4]. Other barriers in adopting such indicators are the cost of adaptation, specifically for smaller governments, and lack of perceived benefit from international exposure and comparison. Other studies indicate a problem that arises in indicator-based comparisons, as the comparison might be invalid due to inconsistencies in the data used to derive them [19]. These studies highlight that the international standards should not only be considered for benchmarking but also be valued for the opportunity they present for comparative learning. In addition, data provenance, reliability, and consistency of analysis need to be evaluated for standards. It is significant and timely to investigate the role of spatial technology and underpinning frameworks such as hierarchy of Spatial Data Infrastructures (SDIs) [7] for supporting the implementation of sustainable development standards in different levels of government.

The crucial role of spatial technologies in capacity building across different levels of governments is emphasised in Articles 159 and 160 of AFINUA. While there are some initiatives for spatial enablement of governments in implementation of SDGs and NUA, there is limited understanding of how these technologies will be helpful. As such, this chapter explores the 35 key elements established by AFINUA and highlights the current spatial enablement initiatives that provide opportunity to implement these elements. This chapter is for decision-makers and urban and regional planners at different levels of government in local, state and national scales.

This chapter continues with providing a historical account of how global urbanisation began to be considered a threat and how it ended up as a potential development tool for the future generation established by the New Urban Agenda. The next section introduces the elements of action framework for the implementation of NUA. The principles of spatial enablement and some of the international initiatives will be presented in section three. The fourth section draws links between spatial enablement concepts and principles and the key elements of AFINUA. Finally, the last section of the chapter discusses some implications of implementing the spatial enablement framework for successful achievement of sustainable development. This chapter will come to an end with describing the future opportunities in research and capacity development in support of evidence-based and data-driven urban policy and planning. 


\subsection{Urbanisation; From a Threat to an Opportunity}

The United Nations Conferences on Human Settlements, where a significant number of city governments and urban management officials are in attendance, have sought approaches to improving the urban quality of life. In the early 1970s, the global strategy to address challenges of human settlements was sought and, at the same time, the United Nations Resolution on Housing, Building and Planning was produced. However, one of the major issues raised was rapid urbanisation, which required a response to the emergence of large unmanageable slums with poor access to basic services including water and sanitation.

Accordingly, in 1976 the Vancouver Declaration on Human Settlements highlighted critical actions and requirements to improve the quality of life in all human settlements. This was the time that the United Nations Conference on Human Settlements (Habitat I) elaborated on issues of unplanned urbanisation, which resulted in overcrowded cities without corresponding capacity to provide basic services. Addressing these challenges, the UN General Assembly established UN-Habitat as a focal point for human settlements action. In addition, a year after the Vancouver declaration, the UN established its Center for Human Settlements (UNCHS/Habitat). However, despite these advances, poor living conditions in human settlements remained a persistent issue.

The global urban population soared dramatically and by $199042.5 \%$ of global population was urban; during this time ten megacities emerged with populations of 10 million or more. This led to the 1996 Istanbul Declaration on Human Settlements and a strengthening in the role and capability of the UN Center for Human Settlements (UNCHS). UN-Habitat II was held at the same time and HABITAT AGENDA was adopted. This agenda particularly emphasised promoting the provision of adequate shelters and basic services to familiarise sustainable human settlements.

In 2000, eight Millennium Development Goals (MDGs) were adopted by the United Nations. These goals, which targeted for 2015, range from reducing extreme poverty rates by $50 \%$ to fighting against the spread of HIV/AIDS and providing universal primary education. The MDGs set to respond to the challenges of urban inequality, slums, poverty, and environmental degradation. As a result of implementing MDGs, between 2000 and 2014, more than 320 million people living in slums gained access to improved water sources, improved sanitation facilities, or durable or less crowded housing. However, in 2015 more than 880 million people were estimated to be living in slums, compared to 792 million in 2000 and 689 million in 1990.

The implementation of MDG targets worldwide had been recorded with some progress. Several countries included the Millennium Development Goals (MDGs) into their national and sub-national development plans and strategies, and adopted specific measures with the aim of achieving the associated 
targets [18]. However, the achievements have been uneven across regions and countries, leading to significant gaps [21]. According to the UN report on MDGs in 2015, millions of disadvantage people had not leveraged these goals due to factors such as geographic location, gender, age, ethnicity, and disability [8].

Reaching to the deadline of MDGs in 2015, the discussion around the results and barriers of implementation led to formulating the Sustainable Development Goals (SDGs). Given that the MDGs failed certain people and geographical locations, the SDGs' 2030 Agenda sets out to "reach the furthest behind first" and concludes with a pledge that "no one will be left behind" [18].

Accordingly, In October 2016, the New Urban Agenda was unanimously adopted at the United Nations Habitat III, with the aim of serving as a new vision for cities and municipalities worldwide for the next 20 years [17]. UNDP "demonstrated its full support to the implementation of the New Urban Agenda with the official launch of its Sustainable Urbanization Strategy". This was the first time urbanisation was considered an opportunity for achieving sustainable development, which addresses SDGs, especially Goal 11 on sustainable cities and communities.

In the reviews for implementing NUA the community consultations and inputs from two important expert group meetings held in Surabaya, Indonesia, in July 2016 and New York in April 2017 led to formulating an action framework for implementation of the NUA (AFINUA) [16]. This framework articulated that while the process of achieving the Sustainable Development Goals are important, it cannot replace the outcome. In fact, the specific attention of AFINUA is enumerating desired urban outcomes. As such, the framework set out to assist the local authorities, major groups and relevant stakeholders to measure and monitor the targets they are aiming for.

The AFINUA key elements are also connected to other indicators identified by UN-Habitat's City Prosperity Initiative (CPI). The CPI is a global initiative that aims to turn the data to information and knowledge for cities to measure their performances and establish an evidence-based policy dialogue among decision-makers. The CPI aims to facilitate a higher accountability in the implementation of the SDGs and NUA [19]. This initiative and associated tools have been used individually or in combination with other indexes in evaluating several cities worldwide in monitoring sustainability performance [23], multi-scale sustainability evaluation [22], environmental quality [1], and urban resilience [13].

Like AFINUA, there have been other action guidelines established for localising the implementation of SDGs. In Europe, the Association of Flemish Cities and Municipalities (VVSG) worked with local authorities to translate the SDGs at the local level [5]. They published several tools and guidelines to help local authorities in monitoring and exploring the ways to generate a broader SDG policy in their respective legislation. VVSG transferred the focus of achieving SDGs to taking specific actions and raising awareness of this 
global ambition among residents, in government, and in industry. In the next section, the principles of the AFINUA and CPI are described in terms of how they are set for global action.

\subsection{AFINUA and Its Relation to SDGs and CPI}

The action framework for implementing new urban agenda, groups 35 key elements into the NUA's five pillars: (1) national urban policies, with six key elements, (2) urban legislation, rules and regulations, with nine key elements, (3) urban planning and design, with eight key elements, (4) urban economy and municipal finance, with six key elements, and (5) local implementation, with six key elements. While the NUA is exclusive to SDG Goal 11, other goals and targets provide urban-critical sectoral and cross-cutting areas. Some examples are the food security and urban-rural linkage relevant to Goal 2; health as a critical urban factor in Goal 3; education and culture is considered in Goal 4; gender equity reflected in Goal 5; water challenges in Goal 6; energy as a major concern in cities reflected in Goal 7; employment and GDP indicated in Goal 8; sustainable consumption and production in Goal 12; and climate change impacts in cities included in Goal 13. As such, these relations are sought in formulating the AFINUA elements [16].

In addition, the connection of AFINUA to CPI is through six dimensions set by the UN-Habitat:

a. Productivity (CPI-P):This dimension measures the average achievements of the cities in terms of creating wealth and how it's shared, or cities contribution to economic growth and development, generation of income, provision of decent jobs and equal opportunities for all.

b. Infrastructure Development (CPI-ID):The Infrastructure dimension measures the average achievement of the city in providing adequate infrastructure for accessing clean water, sanitation, good roads, and information and communication technology - in order to improve living standards and enhance productivity, mobility and connectivity.

c. Quality of Life (CPI-QoL):The quality of life dimension measures the cities' average achievement in ensuring general wellbeing and satisfaction of the citizens.

d. Equity and Social Inclusion (CPI-ESI):The Equity and Social inclusiEquity and Social Inclusion (CPI-ESI):on dimenion measures the cities' average achievements in ensuring equitable (re)distribution of the benefits of prosperity, reduces poverty and the incidence of slums, protects the rights of minority and vulnerable groups, enhances gender equality, and 
ensures equal participation in the social, economic, political and cultural spheres.

e. Environmental Sustainability (CPI-ES):The Environmental Sustainability dimesion measures the average achievement of the cities in ensuring the protection of the urban environment and its natural assets. This should be done simultaneously while ensuring growth, pursuing energy efficiency, reducing pressure on surrounding land and natural resources and reducing environmental losses through creative and environment-enhancing solutions. [15].

Figure 12.1 summarises the connection of AFINUA elements with SDGs for National Urban Policies. The details of these connections and their local actors can be found in [16].

\section{National Urban Policies nUA pillar}

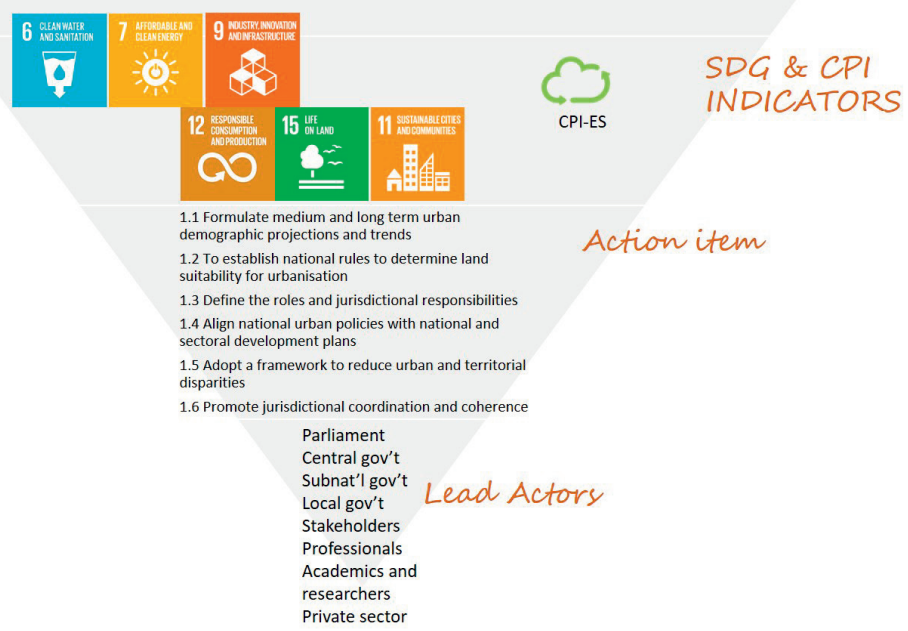

\section{FIGURE 12.1}

The Connection of AFINUA Elements for National Urban Policies Domain of NUA

One of the major requirements for ensuring implementation of items set by AFINUA is a robust data infrastructure. This is significant because the implementation needs ongoing control, measurement, and monitoring of the AFINUA-related SDG and CPI indicators. The next section briefly explains the overall components of a reliable data infrastructure for this purpose. 


\subsection{Spatial Data Infrastructure Advancements and Op- portunities}

The MDG report in 2015 indicated the importance of sustainable data for sustainable development [8]. This report regarded the data as an "indispensable element of the development agenda". In particular, this report indicated how the local data is important for measuring and monitoring subnational performances. The demand and policy making are regarded as two significant drivers for data improvements, and while there have been several initiatives for improvements of data collection worldwide, the critical data for policy making was still lacking [18].

In transformation from MDGs to SDGs, one of the main issues was the lack of quality data to enable regular monitoring and support evidence-based decision making. As such, several suggestions were made by international entities including UNDP, World Bank Group, and UN-Habitat to support evidencebased decision making. These suggestions include using real-time data, adopting geospatial data, strengthening statistical capacity, utilising new technologies, changing the methods of data collection and dissemination, developing global standards for integrated statistical systems, and promoting open data $[8,18]$.

However, several studies reported that many governments worldwide lack awareness, realising the importance of geospatial information and related technologies in enabling the implementation of SDGs. This lack of awareness is particularly at the policy and decision-making level, which hinders enabling robust tools such as National Spatial Data Infrastructures [14].

While the national policy makers are yet to fully implement the data policy in support of sustainable development, the international entities have provided several frameworks and standard guidelines, which have been used for developing system architectures as enablers for deriving several city and regional indicators in an ad hoc fashion.

At the United Nations level, several initiatives including UN-Global SDG Database $^{1}$ is available for access to data, which is compiled through the UN System in preparation for the Secretary-General's annual report on "Progress towards the Sustainable Development Goals". However, this data is not spatially enabled and remains at a national level, which provides only a limited understanding of the local performances. In addition, recently an Open SDGs Data Hub ${ }^{2}$ was developed to fully implement and monitor progress on the SDGs. This platform aims to support decision makers everywhere, who need accurate and timely data and statistics. So far, however, limited countries have committed to this platform and the available data has limited capability for local governments.

\footnotetext{
${ }^{1}$ https://unstats.un.org/sdgs/indicators/database/

${ }^{2}$ http://www.sdg.org/
} 
In the international technology standard community, Open Geospatial Consortium (OGC) formulated an enterprise framework to derive indicators for sustainable development and resilience of communities (ISO 37120) [9]. The OGC framework is considered to be based on cloud computing. This framework, which is called the OGC Smart Cities Spatial Information Framework, incorporates four layers of sensing (real-time data), data (access and quality checking), business (analysis and visualisation), and application (e.g. health, education, public safety and security, and urban planning). Figure 12.2 shows the components of OGC enterprise framework for smart cities.

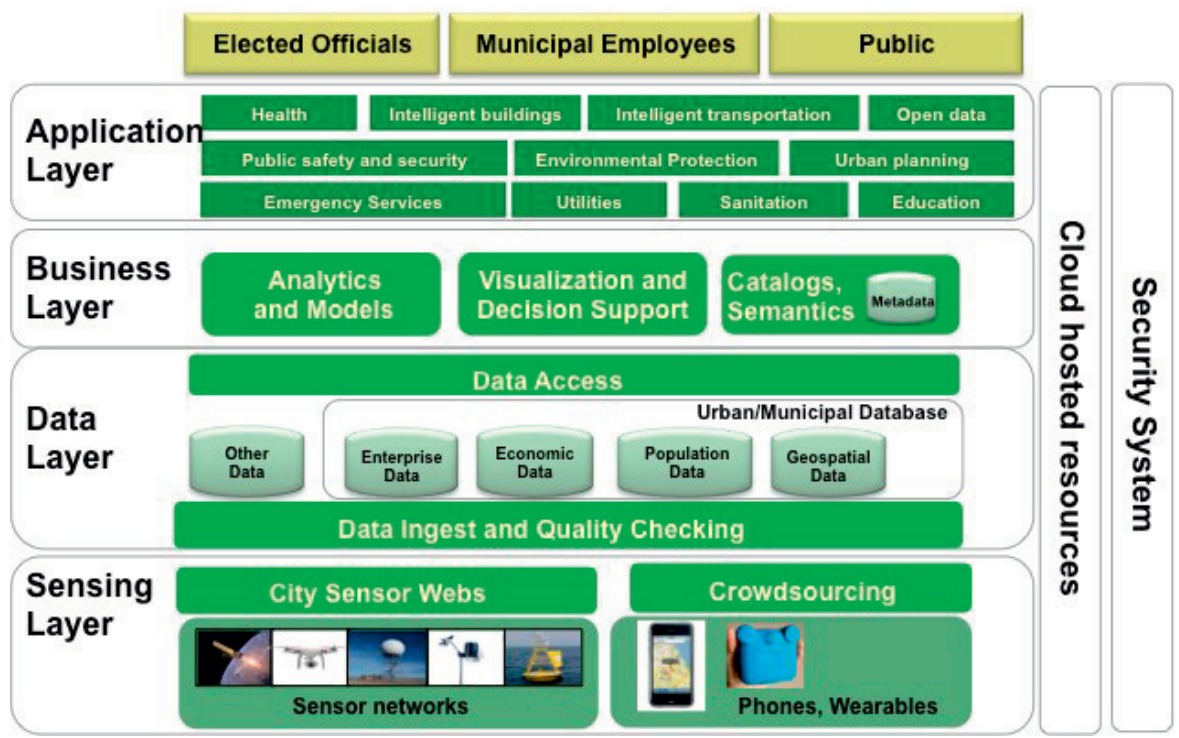

\section{FIGURE 12.2}

OGC enterprise framework for Smart Cities adopted from [9].

Several initiatives worldwide have implemented spatial data infrastructures addressing the components of the OGC framework. The examples are Australian Urban Research Infrastructure Network (AURIN), which is an einfrastructure to support urban and built environment research in Australia. AURIN facilitates access to more than 2500 datasets across Australia, enabling researchers and data providers to integrate data, analyse and visualise several different urban and built environment data [11]. Another example is the Urban Big Data Centre (UBDC), an initiative by the UK Economic and Social Research Council at the University of Glasgow, in partnership with six other UK universities. The role of UBDC is to manage, link and analyse massive amounts of multi- sectoral urban open and authorised data in a portal allowing diverse users to conduct research and analysis ${ }^{3}$. Similarly, the

\footnotetext{
${ }^{3}$ http://ubdc.ac.uk/
} 
Urban Centre for Computation and Data (UrbanCCD) at the University of Chicago has developed a platform called Plenarion to facilitate urban data discovery, exploration, and application of open city data [2]. However, most of these systems lack real-time data analysis as well as a semantic enablement layer for harmonising the fragmented and heterogeneous spatial data [10]. In addition, some of these infrastructures are yet to be used in deriving the SDG and CPI indicators as well as providing reliable sources for local, subnational, and national policy makers. A potential explanation for this might be that the sustainable development standards and indicators are too broad to be derived in smaller geographical boundaries than states and national levels. In addition, the national and international data policies are not reflecting the requirements of SDG and CPI.

Moreover, the lack of semantic enablement layer is an important one to address as AFINUA elements and associated SDG and CPI indicators are comprised of multi-disciplinary domains and fragmented data sources with heterogenous structures [3]. The semantic enablement methods and associated architectures will be presented in other chapter on enabling tools and technical components.

As such, while there are several national and international initiatives, standards and frameworks for spatial data infrastructures, they are not fully committed to enable the implementation, measuring and monitoring of the sustainable development indicators and localised NUA initiatives that set the future agenda for research and policy making.

\subsection{Conclusion and Discussion}

This chapter is intended to highlight the localising steps taken for implementation of SDGs in urban and territory environments. In addition, it highlighted several technological and spatial data initiatives worldwide that can potentially act as enablers for implementing, measuring, and monitoring the localised Sustainable Development Goals.

The literature and evaluation reports on SDGs indicated the weak connection between decision making and government policies and the standard indicators. This limited connection was attributed to the lack of robust data and various interpretation on the standards and indicators, and as a result the roles of Spatial Data Infrastructures and new technologies have been highlighted in several reports and studies.

While there is an emphasis on the critical role of spatial technologies for implementing the New Urban Agenda (articles 159 and 160 of AFINUA), this chapter highlights the lack of data standards and policy to address the AFINUA requirements. As such, two major aspects need to be addressed for local implementation and monitoring of New Urban Agenda and associated 
Sustainable Development Goals. First, the broadness of the sustainable development standards and indicators and their definitions, which limits them to be derived in smaller spatial levels such as statistical areas or suburbs. Second, the national and international data policies need to be revisited to reflecting the requirements of sustainable development indicators such as SDG and CPI.

\section{Bibliography}

[1] Marino Bonaiuto, Ferdinando Fornara, Silvia Ariccio, Uberta Ganucci Cancellieri, and Leila Rahimi. Perceived residential environment quality indicators (preqis) relevance for un-habitat city prosperity index (cpi). Habitat International, 45:53-63, 2015.

[2] Charlie Catlett, Tanu Malik, Brett Goldstein, Jonathan Giuffrida, Yetong Shao, Alessandro Panella, Derek Eder, Eric van Zanten, Robert Mitchum, Severin Thaler, et al. Plenario: An open data discovery and exploration platform for urban science. IEEE Data Eng. Bull., 37(4):27-42, 2014.

[3] Yiqun Chen, Soheil Sabri, Abbas Rajabifard, and Muyiwa Elijah Agunbiade. An ontology-based spatial data harmonisation for urban analytics. Computers, Environment and Urban Systems, 72:177-190, 2018.

[4] Derui Deng, Shiyao Liu, Lawrence Wallis, Elizabeth Duncan, and Phil McManus. Urban sustainability indicators: how do australian city decision makers perceive and use global reporting standards? Australian geographer, 48(3):401-416, 2017.

[5] Bart Van Herck, Valentijn Vanoeteren, and Katrin Janssen. Local indicators for the 2030 agenda (sustainable development goals), 2019. Brussels, Belgium.

[6] Robert W Marans. Quality of urban life \& environmental sustainability studies: Future linkage opportunities. Habitat International, 45:47-52, 2015 .

[7] Ian Masser, Abbas Rajabifard, and Ian Williamson. Spatially enabling governments through sdi implementation. International Journal of Geographical Information Science, 22(1):5-20, 2008.

[8] United Nations. The Millennium Development Goals Report 2015. 2015.

[9] George Percivall, C Ronsdorf, S Liang, D McKenzie, and L McKee. Ogc smart cities spatial information framework. OGC Internal reference, (14115), 2015. 
[10] Abbas Rajabifard, Serene Ho, and Soheil Sabri. Urban analytics data infrastructure: Critical sdi for urban management in australia. SMART WORLD, page 95, 2016.

[11] Soheil Sabri, Christopher J Pettit, Mohsen Kalantari, Abbas Rajabifard, Marcus White, Oliver Lade, and Tuan Ngo. What are essential requirements in planning for future cities using open data infrastructures and 3d data models. In Proceedings of the 14th International Conference on Computers in Urban Planning and Urban Management, Cambridge, MA, USA, pages 7-10, 2015.

[12] Soheil Sabri, Abbas Rajabifard, Serene Ho, Mohammad-Reza NamaziRad, and Christopher Pettit. Alternative planning and land administration for future smart cities [leading edge]. IEEE technology and society magazine, 34(4):33-73, 2015.

[13] Holger Schlör, Sandra Venghaus, and Jürgen-Friedrich Hake. The fewnexus city index-measuring urban resilience. Applied energy, 210:382$392,2018$.

[14] Greg Scott and Abbas Rajabifard. Sustainable development and geospatial information: a strategic framework for integrating a global policy agenda into national geospatial capabilities. Geo-spatial Information Science, 20(2):59-76, 2017.

[15] UN-Habitat. The six dimensions of urban prosperity - city prosperity initiative, 2016.

[16] UN-Habitat. Action framework for implementation of the new urban agenda, 2017.

[17] UN-Habitat. The new urban agenda, adopted by the united nations on 20 october 2016, quito, ecuador, 2017.

[18] UNDP and World Bank Group. Transitioning from the mdgs to the sdgs, 2016.

[19] Yetian Wang and Mark S Fox. Consistency analysis of city indicator data. In International Conference on Computers in Urban Planning and Urban Management, pages 355-369. Springer, 2017.

[20] Cecilia Wong. A framework for 'city prosperity index': Linking indicators, analysis and policy. Habitat International, 45:3-9, 2015.

[21] Zofia Wysokińska. Millenium development goals/un and sustainable development goals/un as instruments for realising sustainable development concept in the global economy. Comparative Economic Research, 20(1):101-118, 2017. 
[22] Tan Yigitcanlar, Fatih Dur, and Didem Dizdaroglu. Towards prosperous sustainable cities: A multiscalar urban sustainability assessment approach. Habitat International, 45:36-46, 2015.

[23] Bohong Zheng and Komi Bedra. Recent sustainability performance in china: Strength-weakness analysis and ranking of provincial cities. Sustainability, 10(9):3063, 2018. 